\title{
Nonmitochondrial oxygen utilization by rabbit blastocysts and surface production of superoxide radicals
}

\author{
C. Manes ${ }^{1}$ and N. C. Lai ${ }^{2}$ \\ ${ }^{1}$ Department of Biology, University of San Diego, 5998 Alcalá Park, San Diego, CA 92110-2492, USA; \\ and ${ }^{2}$ Veterans Administration Medical Center, San Diego, Research Division - Cardiology, 3350 La Jolla \\ Village Drive, La Jolla, CA 92161, USA
}

\begin{abstract}
A minimum value for nonmitochondrial oxygen utilization in rabbit blastocysts at day 6 post coitum was determined by measuring oxygen consumption in the presence of cyanide. A microcathode oxygen electrode was used to monitor oxygen concentration continuously during blastocyst incubation in a newly devised culture medium, and the uninhibited blastocyst was found to consume $2.79 \pm 0.09 \mu \mathrm{O}_{2} \mathrm{~h}^{-1} \mathrm{~cm}^{-2}$. This rate was reduced by $51 \%$ in the presence of $1 \mathrm{mmol} \mathrm{KCN}{ }^{-1}$. The addition of nitroblue tetrazolium to the cyanide-containing medium reduced net oxygen consumption by an additional $23 \%$ as the nitroblue tetrazolium was reduced to formazan. The ability of rabbit blastocysts to reduce nitroblue tetrazolium in the presence of cyanide was investigated using a spectrophotometric assay. Fractionation of blastocyst cells revealed that the enzymatic activity chiefly responsible for formazan production partitioned with the membrane/particulate fraction and could be solubilized by the detergent NP40. The enzyme was NAD $(\mathrm{P}) \mathrm{H}$-dependent, did not require divalent cations for activity, and appeared to contain no haeme moiety. The rate of formazan production in the spectrophotometric assay was markedly reduced by the presence of superoxide dismutase. The oxygen electrode and spectrophotometer data indicate that there is a superoxide-generating $\mathrm{NAD}(\mathrm{P}) \mathrm{H}$ oxidase on the blastocyst surface. Calculations based on the average surface area of rabbit blastocysts at day 6 show that these embryos can produce at least 8 nmoles of superoxide per embryo $\mathrm{h}^{-1}$. Potential deciduogenic effects of blastocyst-derived superoxide and its dismutated product, hydrogen peroxide, are discussed.
\end{abstract}

\section{Introduction}

In rabbits, the earliest signs of an endometrial reaction to the blastocyst have been detected at day 6 post coitum; this is $24 \mathrm{~h}$ before the trophoblast penetrates the blastocyst covering and begins to fuse with the endometrial epithelium (Schlafke and Enders, 1975). At day 6 post coitum, the rapidly expanding rabbit blastocysts are spaced along the uterine horns and are virtually immobilized because of their size. At this time the endometrium directly apposed to a blastocyst shows a fivefold increase in phospholipase activity (Hoffman et al., 1984), as well as selective expression of the $25 \mathrm{kDa}$ gap junction protein (Winterhager $e t$ al., 1988). These early responses are followed by increased vascular permeability, detectable by day 6.5 post coitum (Hoos and Hoffman, 1980), and by marked local thickening of the endometrial stroma (the decidual reaction) by day 8 (Amoroso, 1964).

Among the chemical signals that may be involved in this blastocyst-endometrial interaction, prostaglandins appear to have a central role (Kennedy, 1983). In rabbits, the blastocyst (Dey et al., 1980; Racowsky and Biggers, 1983) and the endometrium (Hoffman et al., 1984) can synthesize prostaglan-

Received 14 November 1994 dins. Arachidonic acid, the substrate for prostaglandin synthesis, is a strong deciduogenic agent in the uterus of the progestational rabbit (Hoffman et al., 1977). Since arachidonic acid is released from membrane phospholipids by phospholipases, chiefly by phospholipase $\mathrm{A}_{2}$ (Halliwell and Gutteridge, 1989), the local increase in phospholipase activity found on day 6 post coitum (Hoffman et al., 1984) could initiate the decidual cell reaction in the endometrium. Thus, on day 6 , the blastocyst signal should be capable of stimulating phospholipase activity.

A role for reactive oxygen species in blastocyst signalling in rabbits has been implicated by the cytochemical finding of hydrogen peroxide production on the surface of rabbit blastocysts facing the endometrium (Manes, 1992). Hydrogen peroxide is the central member of the reactive oxygen species group, being formed by the dismutation of superoxide, with which it can subsequently react to yield hydroxyl radicals (Halliwell and Gutteridge, 1989). The presence of hydrogen peroxide on the trophoblast surface therefore implies the presence of the other two species. Hydrogen peroxide appears between day 4 and day 5 post coitum and persists for the remainder of the preimplantation period (Manes, 1992). Not only do reactive oxygen species stimulate phospholipase activity (Carlson and $\mathrm{Wu}, 1991$ ), but an inorganic source of 
reactive oxygen species, such as copper wire (Oster and Oster, 1974), elicits an intense decidual response in the endometrium of the progestational rabbit (Tobert, 1975).

The study reported here was undertaken to confirm and quantitate the cytochemical finding. The enzymatic activity producing hydrogen peroxide on the trophoblast is cyanide resistant (Manes, 1992); thus, a primary aim of this study was to determine whether cyanide-resistant oxygen consumption by rabbit blastocysts at day 6 could be detected in a microrespiration cell. Nitroblue tetrazolium was used to estimate minimum amounts of superoxide and hydrogen peroxide produced by individual rabbit blastocysts at day 6 , as well as to characterize the $\mathrm{NAD}(\mathrm{P}) \mathrm{H}$ oxidase chiefly responsible for superoxide production in a spectrophotometric assay (Oberley and Spitz, 1985).

\section{Materials and Methods}

\section{Embryos}

Blastocysts were collected from normally ovulating New Zealand White does at day $6 \pm 2 \mathrm{~h}$ post coitum and placed immediately into the defined sterile culture medium described by Manes (1992) and modified for these studies by omitting copper and manganese. The culture was maintained at $37-38^{\circ} \mathrm{C}$ on a warming tray. The blastocysts were washed twice in $10 \mathrm{ml}$ of this medium to remove adherent blood cells. The maximum and minimum diameters of each blastocyst were measured with an ocular micrometer; surface areas were calculated using the formula for a prolate spheroid.

\section{Measurement of oxygen uptake}

Pooled, washed blastocysts were divided randomly into groups of 3-5 for determination of oxygen uptake. The group of blastocysts was placed into a microrespiration cell (Strathkelvin Model RC200, Glasgow) containing $1.0 \mathrm{ml}$ of the culture medium (Manes, 1992) maintained at $38.5^{\circ} \mathrm{C}$. The medium was stirred gently throughout the period of the assay. Oxygen tension in the medium was determined continuously with a microcathode oxygen electrode (Strathkelvin Model 1302) and monitored by a Strathkelvin Instant Oxygen Meter (Model 781). When required, $10 \mu \mathrm{l}$ from $\times 100$ stock solutions were added to the medium in the chamber using a Hamilton syringe with the needle inserted through a slot in the electrode seal. For all measurements, the blastocysts remained fully expanded throughout the period of the assay.

The rate of change of oxygen tension in the respiration chamber was determined from the slope of the first order regression from the digitized data. Oxygen utilization by the microcathode electrode in culture medium alone was measured immediately before introducing each group of embryos into the respiration chamber and was subtracted from the experimental values for that group. Oxygen consumption by blastocysts was calculated from their total surface area $\left(\mathrm{cm}^{2}\right)$ divided by the combined products of the culture medium volume $(1 \mathrm{ml})$, the rate of change in oxygen tension $\left(\right.$ Torr $\left.^{-1}\right)$ and the oxygen solubility coefficient of the culture medium $(1.2 \mu \mathrm{mol}$ $\mathrm{O}_{2} \mathrm{l}^{-1}$ Torr $^{-1}$ ).

\section{Determination of $N A D(P) H$ oxidase activity}

Groups of 10-15 washed blastocysts were pooled, removed from the zonae pellucidae with needles, opened widely to allow escape of all fluid, and then transferred by capillary pipette to a $10 \mathrm{ml}$ wash in PBS. These collapsed blastocysts were then transferred to a $400 \mu \mathrm{l}$ Eppendorf tube and pelleted by centrifugation at $15000 \mathrm{~g}$ for $3 \mathrm{~s}$ in a microfuge. The PBS supernatant was removed by aspiration.

For lysate assays, the cell pellet was resuspended in 100$300 \mu \mathrm{l}$ of $50 \mathrm{mmol}$ sodium phosphate $\mathrm{l}^{-1}$ buffer, $\mathrm{pH} 7.5$, containing $0.3 \% \quad \mathrm{NP} 40 \quad(\mathrm{v} / \mathrm{v})$ (Particle Data Laboratories, Elmhurst, IL) and $5 \mu \mathrm{g}$ soybean trypsin inhibitor $\mathrm{ml}^{-1}$ (Sigma, St Louis, MO) and allowed to stand for $10 \mathrm{~min}$ in ice. The cell suspension was then agitated for $5 \mathrm{~s}$ on a vortex mixer followed by centrifugation at $15000 \mathrm{~g}$ for $5 \mathrm{~min}$. Aliquots of this supernatant were assayed for activity in reducing nitroblue tetrazolium in a microcuvette providing a $1 \mathrm{~cm}$ light path through a volume of $50 \mu$ l (Beckman, Fullerton, CA). The reaction mixture consisted of $50 \mu \mathrm{l}$ embryo lysate, $25 \mu \mathrm{l}$ of $150 \mu \mathrm{mol}$ hypoxanthine $1^{-1}$ (Sigma) in water, and $1 \mu \mathrm{l}$ of $4.25 \mathrm{mmol}$ nitroblue tetrazolium $\mathrm{l}^{-1}$ in $10 \%(\mathrm{v} / \mathrm{v})$ dimethylformamide, giving a final concentration of nitroblue tetrazolium of $5.6 \times 10^{-5} \mathrm{~mol} \mathrm{l}^{-1}$ (Oberley and Spitz, 1985). Assays were carried out at room temperature, recording absorbance at $560 \mathrm{~nm}$ at intervals of $1 \mathrm{~min}$. NADH, NADPH and superoxide dismutase (from beef heart, Sigma S2139) were added in $1 \mu$ l volumes. The final concentrations of NADH and NADPH were $190 \mu \mathrm{mol} \mathrm{l}^{-1}$. Superoxide dismutase (Sigma) was diluted in water to provide $1 \mathrm{U} \mu \mathrm{I}^{-1}$. As a control for nonspecific protein effect, superoxide dismutase was held in a boiling water bath for $10 \mathrm{~min}$. All assays were performed at least in duplicate. Blank values were obtained by substituting lysis buffer alone, and were subtracted from experimental values. Blastocyst cellular protein is reported to correlate closely with blastocyst surface area (Morgan and Kane, 1993); therefore, all values for absorbance at $560 \mathrm{~nm}$ were normalized to $100 \mathrm{~mm}^{2}$ of blastocyst surface area.

Crude fractionation of the embryonic cell pellet was carried out by resuspension in $150 \mu \mathrm{l}$ of $50 \mathrm{mmol}$ sodium phosphate buffer $1^{-1}, \mathrm{pH} 7.5$, containing $5 \mu \mathrm{g}$ soybean trypsin inhibitor $\mathrm{ml}^{-1}$ but without NP40. The cells were allowed to swell for $10 \mathrm{~min}$ on ice; they were then homogenized with a sintered glass pestle and centrifuged at $15000 \mathrm{~g}$ for $5 \mathrm{~min}$ in a microfuge. The supernatant was aspirated and designated as the soluble fraction. The pellet was then resuspended in the complete buffer containing NP40 and processed as described above. NADPH was used as substrate in all assays of soluble or pellet fractions.

When required, reaction mixtures were adjusted to $1 \mathrm{mmol}$ KCN $1^{-1}, 3$ mmol EDTA $1^{-1}$ (J. T. Baker, Phillipsburg, NJ),

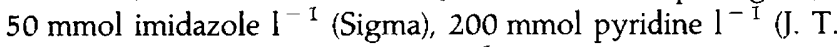
Baker), or $1 \mathrm{mmol}$ allopurinol $\mathrm{l}^{-1}$ (Sigma) by adding the appropriate chemical in $1 \mu l$ of a $\times 77$ stock solution. Allopurinol was solubilized in $100 \mathrm{mmol} \mathrm{NaOH} \mathrm{I}^{-1}$.

\section{Statistical analyses}

Mean values for oxygen consumption by rabbit blastocysts are expressed \pm SEM. Statistical comparisons were determined 


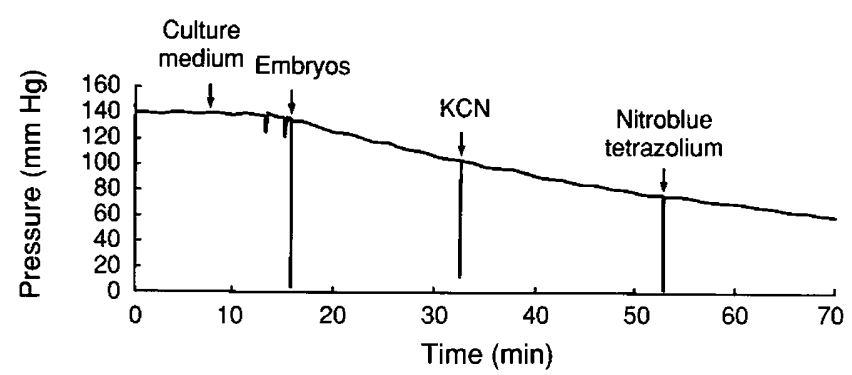

Fig. 1. Oxygen tension in $1 \mathrm{ml}$ of culture medium as a function of time of incubation of rabbit blastocysts. For the measurements illustrated here, three blastocysts at day 6 post coitum recovered from a single doe having a combined surface area of $1.134 \mathrm{~cm}^{2}$ were used. Additions to the culture medium were made at the times indicated (arrows).

by Student's $t$ test with the limit of significance set at $P<0.05$.

\section{Results}

A typical recording of oxygen concentration in the culture medium during blastocyst incubation is shown (Fig. 1). The results of a large series of such measurements of oxygen utilization by the rabbit blastocyst at day 6 , expressed as a function of blastocyst surface area, are summarized (Table 1 ). Under the conditions used, $1 \mathrm{mmol} \mathrm{KCN}{ }^{-1}$ did not abolish embryonic oxygen consumption but reduced it to about half the control value. The addition of nitroblue tetrazolium to the respiration chamber reduced oxygen consumption to about half the $\mathrm{KCN}$-resistant value (Table 1 ). The blastocysts become blue during the first $10 \mathrm{~min}$ of the incubation with nitroblue tetrazolium. Allopurinol also diminished $\mathrm{KCN}$-resistant oxygen consumption, and in combination with nitroblue tetrazolium resulted in an inhibition that, whilst not additive, was greater than that caused by either compound alone (Table 1).

The enzymatic activity responsible for reduction of nitroblue tetrazolium was detectable in homogenates of rabbit blastocysts at day 6 . The activity partitions with the particulate/ membrane fraction and can be solubilized with NP40 (Fig. 2a). NADH and NADPH markedly stimulated the rate of reduction of nitroblue tetrazolium by blastocyst NP40 lysates (Fig. 2b). The rate of reduction in the presence of $\operatorname{NAD}(\mathrm{P}) \mathrm{H}$ was diminished by including native superoxide dismutase in the reaction mixture, whereas the boiled enzyme has no effect (Fig. $2 \mathrm{~b})$. The rate of reduction of nitroblue tetrazolium was not affected by $1 \mathrm{mmol} \mathrm{KCN} l^{-1}, 3 \mathrm{mmol}$ EDTA $l^{-1}, 50 \mathrm{mmol}$ imidazole $\mathrm{l}^{-1}, 200 \mathrm{mmol}$ pyridine $\mathrm{l}^{-1}$ (Fig. 3), or $1 \mathrm{mmol}$ allopurinol $1^{-1}$ (Fig. 4a). Some inhibition of nitroblue tetrazolium reduction by allopurinol was detectable in the absence of $\mathrm{AAD}(\mathrm{P}) \mathrm{H}$ (Fig. $4 \mathrm{~b})$.

\section{Discussion}

At day 6 post coitum the rabbit blastocyst is virtually a monolayer of about 80000 trophoblast cells (Daniel, 1964). The two-layered inner cell mass occupies less than $10 \%$ of the surface area, and widely spaced extra-embryonic endoderm cells have migrated no more than half-way along the inner surface of the trophoblast. The properties described as those of whole blastocysts are therefore principally those of the trophoblast cell population.

The magnitude of the cyanide-resistant fraction of oxygen consumption was not expected, since in earlier work $0.1 \mathrm{mmol}$ cyanide $1^{-1}$ totally abolished oxygen consumption by rabbit blastocysts (Fridhandler et al., 1957; Benos and Balaban, 1980). The reasons for the differences between the results in the work presented here and those of previous investigators are not clear but are likely to include differences in embryo handling and in the culture medium used for respiration measurements. The serum-free medium used to obtain the results reported here is an extensive modification of Ham's F-12 solution with an amino acid composition altered to mimic that of uterine fluids at this stage of pregnancy in rabbits (Jaszczak et al., 1972; Miller and Schultz, 1987). Other modifications are the inclusion of taurine and soybean trypsin inhibitor (Manes, 1992). Blastocysts were collected, maintained and assayed for oxygen uptake in this medium. Blastocysts expand at approximately two-thirds the rate in vivo during culture for $24 \mathrm{~h}$ and display minimal evidence of cell death in the inner cell mass in this medium without serum or other supplements (C. Manes, unpublished). Cyanide at $1 \mathrm{mmol} \mathrm{l}^{-1}$ is more than adequate to inhibit mitochondrial cytochrome oxidase (Mahler and Cordes, 1966). The nonmitochondrial oxygen consumption detected in the present work is thus due to cellular oxygenases and oxidases. However, since several of these potential contributors to oxygen utilization are also sensitive to cyanide (Tanaka and Knox, 1959; Yamamoto and Hayaishi, 1967; Badwey et al., 1981), the cyanide-resistant value of $1.38 \mu \mathrm{O}_{2} \mathrm{~h}^{-1} \mathrm{~cm}^{-2}$ must be viewed as a minimum value for nonmitochondrial oxygen utilization. The cyanide-sensitive fraction was not characterized further.

Reduction of nitroblue tetrazolium has been used for many years to evaluate the cyanide-resistant cell surface $\mathrm{NAD}(\mathrm{P}) \mathrm{H}$ oxidase activity in neutrophils (Baehner and Nathan, 1967). In that situation, nitroblue tetrazolium (NBT) is reduced to formazan by superoxide anions $\left(\mathrm{O}_{2}{ }^{-}\right)$formed on the surface of activated neutrophils:

$$
\mathrm{NBT}^{++}+2 \mathrm{O}_{2}^{-} \rightarrow \text { formazan }+2 \mathrm{O}_{2}
$$

Thus, $\mathrm{O}_{2}$ involved in the production of $\mathrm{O}_{2}{ }^{-}$would be regenerated on an equimolar basis in the presence of nitroblue tetrazolium. In our measurements of $\mathrm{O}_{2}$ concentration in the respiration chamber during blastocyst incubation, net $\mathrm{O}_{2}$ consumption would be reduced to the extent that nitroblue tetrazolium can react with $\mathrm{O}_{2}{ }^{-}$. As the blastocysts become blue due to formazan formation, net $\mathrm{KCN}$-resistant $\mathrm{O}_{2}$ consumption is reduced by about half. This fraction is not only a measure of superoxide production but is also indicative of the availability of superoxide on the blastocyst (trophoblast) surface. Nitroblue tetrazolium is a divalent cation that traverses cell membranes with difficulty (Halliwell and Gutteridge, 1989); in the time span of the oxygen uptake measurements, most of the nitroblue tetrazolium added to the medium would have remained outside the cells. These findings indicate that about $25 \%$ of the oxygen consumed by the rabbit blastocyst at day 6 is used for superoxide production at the trophoblast surface. 
Table 1. Effects of $\mathrm{KCN}$, nitroblue tetrazolium and allopurinol on oxygen consumption by rabbit blastocysts at day 6 post coitum

\begin{tabular}{|c|c|c|c|}
\hline Additions to the incubation medium & $\begin{array}{c}\text { Number of } \\
\text { determinations }\end{array}$ & $\begin{array}{l}\text { Total number of } \\
\text { blastocysts used }\end{array}$ & $\begin{array}{c}\text { Oxygen consumption } \\
\left(\mu 1 \mathrm{O}_{2} \mathrm{~h}^{-1} \mathrm{~cm}^{-2}\right) \\
\text { mean } \pm \text { SEM }\end{array}$ \\
\hline Series 1 & 49 & 178 & \\
\hline None & & & $2.79 \pm 0.09$ \\
\hline $1 \mathrm{mmol} \mathrm{KCN} \mathrm{l}^{-1}$ & & & $1.38 \pm 0.06^{\mathrm{a}}$ \\
\hline Series 2 & 5 & 19 & \\
\hline $1 \mathrm{mmol} \mathrm{KCN} \mathrm{l}{ }^{-1}$ & & & $1.91 \pm 0.05$ \\
\hline$+200 \mu \mathrm{mol}$ nitroblue tetrazolium $\mathrm{I}^{-1}$ & & & $1.02 \pm 0.09^{\mathrm{a}}$ \\
\hline Series 3 & 6 & 26 & \\
\hline $1 \mathrm{mmol} \mathrm{KCN} \mathrm{l}^{-1}$ & & & $1.69 \pm 0.09$ \\
\hline$+1 \mathrm{mmol}$ allopurinol $\mathrm{l}^{-1}$ & & & $0.75 \pm 0.09^{\mathrm{a}}$ \\
\hline Series 4 & 7 & 30 & \\
\hline $1 \mathrm{mmol} \mathrm{KCN} \mathrm{l}^{-1}$ & & & $1.71 \pm 0.08$ \\
\hline+ nitroblue tetrazolium + ailopurinol as above & & & $0.62 \pm 0.07^{\mathrm{a}}$ \\
\hline
\end{tabular}

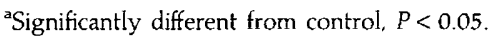
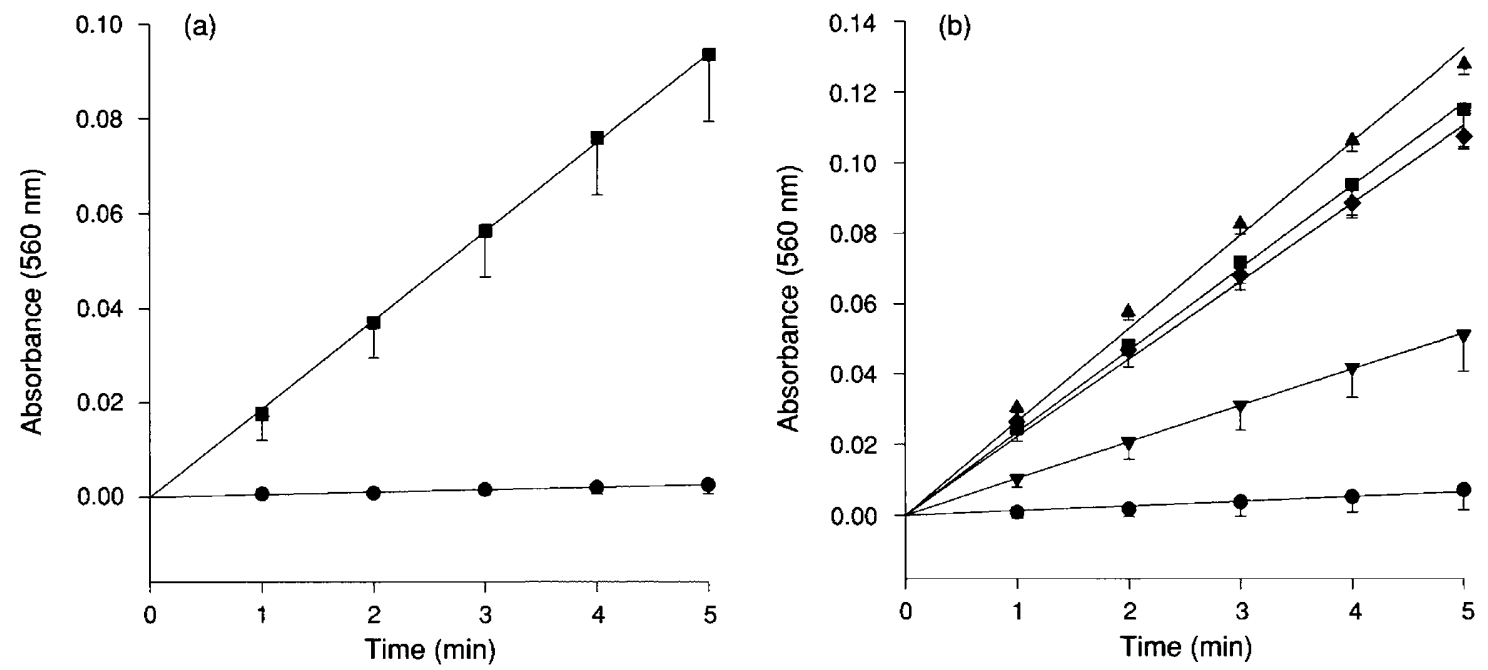

Fig. 2. (a) Reduction of nitroblue tetrazolium by soluble ( $\bullet, n=3$ assays) and pellet ( $\bullet, n=5$ assays) fractions prepared from rabbit blastocysts at day 6 post coitum. NADPH was the substrate provided in these reactions. For these assays, 26 blastocysts recovered from four rabbits were used. (b) Reduction of nitroblue tetrazolium by NP40 lysates of rabbit blastocysts at day 6 post coitum. Additions to the reaction mixture were NADH ( $\Lambda, n=2$ asssays), NADPH ( $\square, n=13$ assays), NADPH plus superoxide dismutase ( $\nabla, n=5$ assays), or NADH plus boiled superoxide dismutase $(\bullet, n=3$ assays). The control reaction containing no additions is indicated by ( $\bullet, n=7$ assays). For these assays, 54 blastocysts recovered from eight rabbits were used. Values are means $\pm \mathrm{SD}$.

The direct measurements of oxygen consumption support the cytochemical results as evidence of a superoxide-generating enzyme that is not inhibited by $1 \mathrm{mmol} \mathrm{KCN} \mathrm{l}^{-1}$. In this respect, the blastocyst enzyme resembles the cell surface $\mathrm{NAD}(\mathrm{P}) \mathrm{H}$ oxidases of neutrophils and sea urchin eggs (Briggs et al., 1975; Turner et al., 1985). In other respects, however, it differs fundamentally. Its insensitivity to 3 mmol EDTA $\mathrm{l}^{-1}$ indicates that it does not require divalent cations, in contrast to the calcium-dependent NADPH oxidase in the sea urchin egg plasma membrane (Turner et al., 1985). Furthermore, its insensitivity to $50 \mathrm{mmol}$ imidazole $\mathrm{l}^{-1}$ or to $200 \mathrm{mmol}$ pyridine $\mathrm{l}^{-1}$ contrasts with the neutrophil surface NAD(P)H oxidase, which is strongly inhibited by these agents by virtue of its haeme centre (lizuka et al., 1985). The blastocyst enzyme thus appears to be a new member of the group of cell surface $\mathrm{NAD}(\mathrm{P}) \mathrm{H}$ oxidases.

It should be noted that the blastocyst enzyme would be well supplied with substrate. Rabbit blastocysts actively use the hexose monophosphate pathway (Fridhandler, 1961). The high rate of nucleic acid synthesis occurring in these embryos (Karp et al., 1973) implicates this pathway in the provision of the requisite ribose. The NADPH generated must be reoxidized to maintain the hexose monophosphate pathway. A model for the trophoblast surface oxidase that is consistent with its two 

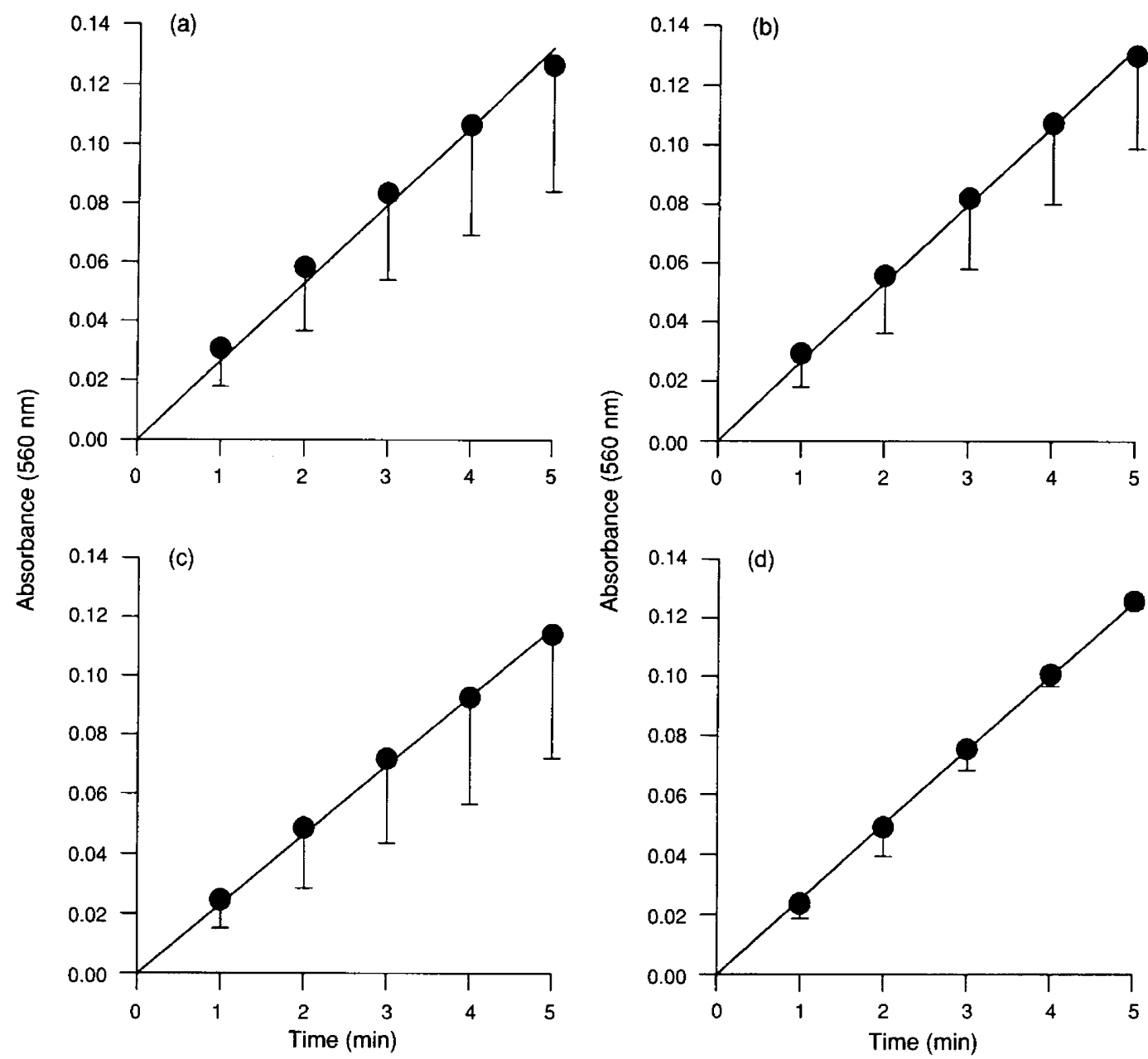

Fig. 3. Reduction of nitroblue tetrazolium by NP40 lysates of rabbit blastocysts at day 6 post coitum in the presence of (a) $1 \mathrm{mmol} \mathrm{KCN}{ }^{-1}$ (3); (b) $3 \mathrm{mmol} \mathrm{EDTA}{ }^{-1}$ (3); (c) $50 \mathrm{mmol}$ imidazole $\mathrm{l}^{-1}$ (2) and (d) 200 mmol pyridine $1^{-1}$ (3). NADPH was the substrate provided in all of the reactions shown. Numbers in parentheses refer to the number of assays carried out. For these assays, 33 blastocysts recovered from five rabbits were used. Values are means $\pm \mathrm{SD}$.

functions would place the $\mathrm{NAD}(\mathrm{P}) \mathrm{H}$ binding site on the cytosolic face of a transmembrane protein and the oxygenbinding site on the exterior.

The enzymatic activities responsible for the remainder of the $\mathrm{KCN}$-resistant oxygen utilization have not been completely identified. Allopurinol increased the inhibition caused by nitroblue tetrazolium alone. A low rate of allopurinolinhibitable reduction of nitroblue tetrazolium was detectable in the absence of $\mathrm{NAD}(\mathrm{P}) \mathrm{H}$ in the cuvette assay. These findings, together with the recent identification of xanthine oxidase cDNA clones in a recombinant library prepared from rabbit blastocysts at day 6 (C. Manes, unpublished), indicate that xanthine oxidase is present and active in rabbit embryos at this stage. The low activity seen in the cuvette assay contrasts with the prominent effect on oxygen consumption in the respiration chamber, and suggests that allopurinol may have nonspecific effects on oxygen utilization beyond its specific inhibition of xanthine oxidase. It should be stressed that allopurinol shows no inhibition of $\mathrm{NAD}(\mathrm{P}) \mathrm{H}$-stimulated reduction of nitroblue tetrazolium which clearly differentiates this enzyme from xanthine oxidase. It is very likely that other enzymes are also contributing to $\mathrm{KCN}$-resistant oxygen utilization by rabbit blastocysts.

The surface area of the average rabbit blastocyst at day 6 is $25 \mathrm{~mm}^{2}$ (Daniel, 1964; and present data). Given a total oxygen consumption of approximately $2.8 \mu \mathrm{l} \mathrm{h}{ }^{-1} \mathrm{~cm}^{-2}$, the average blastocyst at day 6 would consume $30 \mathrm{nmol} \mathrm{O}_{2} \mathrm{~h}^{-1}$. If, as indicated by the data presented, approximately $25 \%$ of this $\mathrm{O}_{2}$ is being converted to superoxide at the trophoblast surface, superoxide is being produced at a rate of about $8 \mathrm{nmol} \mathrm{h}^{-1}$. Two moles of superoxide are required to yield one mole of hydrogen peroxide by dismutation (Halliwell and Gutteridge, 1989). The potential yield of hydrogen peroxide from the surface of the average blastocyst at day 6 is thus about $4 \mathrm{nmol} \mathrm{h}^{-1}$.

Any hydrogen peroxide generated at the trophoblast surface would be separated from the endometrial epithelium only by the thinning blastocyst covering (Denker and Gerdes, 1979) through which it can diffuse with the same ease as water molecules (Halliwell and Gutteridge, 1989). Transient or steady-state concentrations of hydrogen peroxide in this trophoblast-endometrial space are unknown, but it should be 

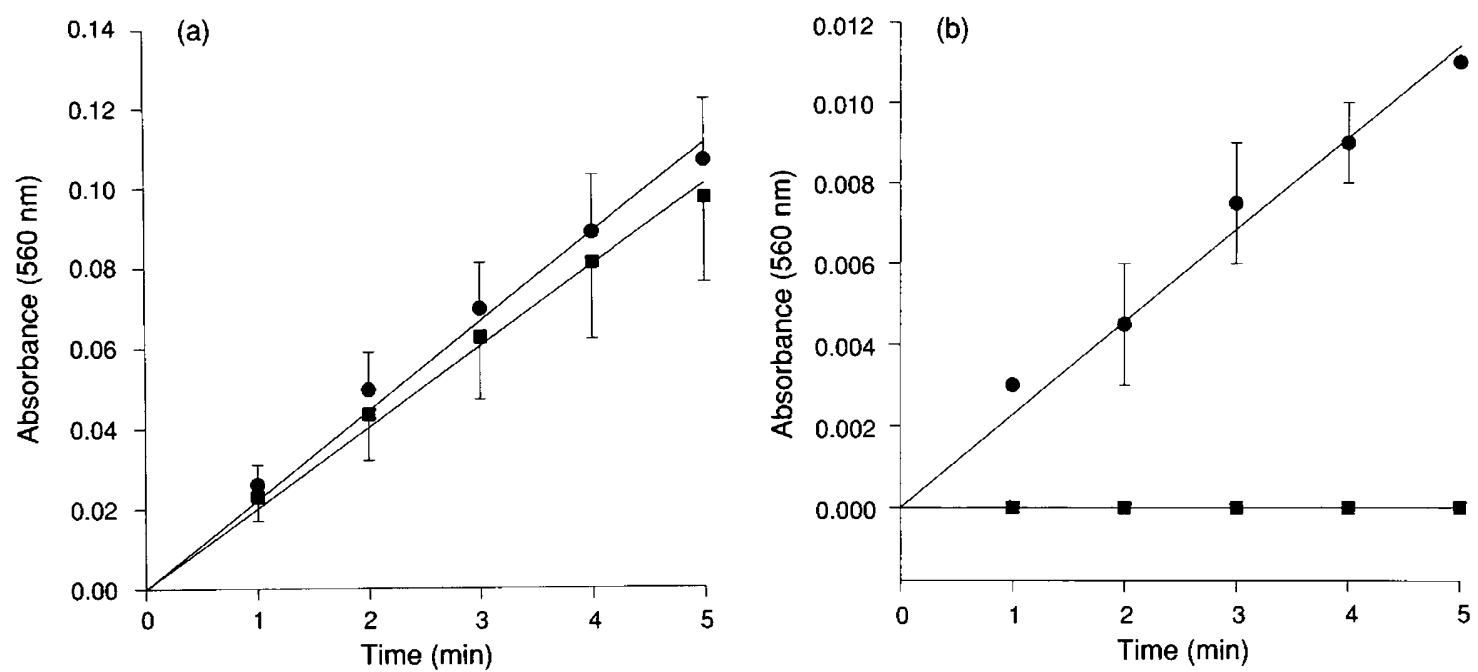

Fig. 4. Reduction of nitroblue tetrazolium by NP40 lysates of rabbit blastocysts at day 6 post coitum in the presence ( $\square$, $n=2$ asssays) or absence ( $\bullet, n=2$ assays) of $1 \mathrm{mmol}$ allopurinol $1^{-1}$. (a) NADPH was provided as substrate in these reactions. (b) NADPH was not provided. For the assays shown in (a) and (b), 40 blastocysts recovered from five rabbits were used. Values are means $\pm \mathrm{SD}$.

noted that hydrogen peroxide can exert significant biological effects at micromolar concentrations. At $100 \mu \mathrm{mol}^{-1}$, hydrogen peroxide mimics many of the effects of insulin on adipocytes (Mukherjee, 1980). At $300 \mu \mathrm{mol} 1^{-1}$ it exerts maximum stimulation of cyclooxygenase, the initial enzyme in prostaglandin synthesis (Morse et al., 1977; Cherouny et al., 1988), while at $400 \mu \mathrm{mol}^{-1}$, it stimulates cytosolic guanylyl cyclase (Burke and Wolin, 1987), activates transcription factor NF-KB (Schreck $e$ al., 1991) and induces the transcription of proto-oncogenes c-myc and c-fos (Rao and Berk, 1992). Catalase activity in the endometrial secretions or epithelium would not necessarily negate a paracrine role for hydrogen peroxide. In fact, Burke and Wolin (1987) found that catalase is required for the stimulation of guanylyl cyclase activity by hydrogen peroxide. It appears that in this system the hydrogen peroxide-catalase complex is the effective activator of guanylyl cyclase. The sensitivity and relevant responses of the endometrium of the progestational rabbit to exogenous hydrogen peroxide remain to be investigated.

Of equal importance in the blastocyst-endometrial interaction is the possibility of generating hydroxyl radicals via the Fenton reaction, in which the reaction of hydrogen peroxide with superoxide is catalysed by trace metals (Halliwell and Gutteridge, 1989). Hydroxyl radicals are capable of initiating peroxidation of membrane fatty acids, which then sets in motion a chain reaction of further lipid peroxidation (Halliwell and Gutteridge, 1989). The lipid hydroperoxides that result can directly stimulate phospholipase $A_{2}$ at $100 \mu \mathrm{mol} 1^{-1}$ (Chakraborti et al., 1989). Lipid hydroperoxides have been found to stimulate cyclooxygenase activity in vitro at concentrations as low as $10^{-8} \mathrm{~mol} \mathrm{l}^{-1}$ (Marshall et al., 1984).

In summary, we have demonstrated that cyanide-resistant oxygen consumption by rabbit blastocysts at day 6 can be readily detected and quantitated. About half of this cyanideresistant fraction results in the production of superoxide at the blastocyst (trophoblast) surface. In conjunction with the cytochemical evidence of hydrogen peroxide on the trophoblast surface (Manes, 1992), it is reasonable to infer the additional presence of hydroxyl radicals. The initiating enzyme is a cyanide-resistant $\mathrm{NAD}(\mathrm{P}) \mathrm{H}$ oxidase on the trophoblast surface which has properties that distinguish it from previously described cell surface $\mathrm{NAD}(\mathrm{P}) \mathrm{H}$ oxidases. This enzyme is active at the time when early endometrial responses to the blastocyst are detectable, and possible roles for the reactive oxygen species generated include stimulation of phospholipase and cyclooxygenase activities, which appear to be central to the decidual response.

C. Manes acknowledges support from the Research Foundation. N. C. Lai was supported by a Merit Grant from the US Veterans Administration.

\section{References}

Amoroso EC (1964) Placentation. In Marshall's Physiology of Reproduction Vol. 2 pp 127-311 Ed. AS Parkes. Longmans, London

Badwey JA, Robinson JM, Karnovsky MJ and Karnovsky ML (1981) Superoxide production by an unusual aldehyde oxidase in guinea pig granulocytes: characterization and cytochemical localization Journal of Biological Chemistry $256 \quad 3479-3486$

Baehner RL and Nathan DG (1967) Leukocyte oxidase: defective activity in chronic granulomatous disease Science 155 835-836

Benos DJ and Balaban RS (1980) Energy requirements of the developing mammalian blastocyst for active ion transport Biology of Reproduction 23 941-947

Briggs RT, Drath DB, Karnovsky ML and Karnovsky MJ (1975) Localization of NADH oxidase on the surface of human polymorphonuclear leukocytes by a new cytochemical method Journal of Cell Biology 67 566-586

Burke TM and Wolin MS (1987) Hydrogen peroxide elicits pulmonary arterial relaxation and guanylate cyclase activation American Journal of Physiology $252 \mathrm{H} 721-\mathrm{H} 732$

Carlson JC and Wu XM (1991) Stimulation of phospholipase $A_{2}$ by xanthine oxidase Biology of Reproduction (Supplement) 44111 (Abstract)

Chakraborti S, Gurtner GH and Michael JR (1989) Oxidant-mediated activation of phospholipase $\mathrm{A}_{2}$ in pulmonary endothelium American Journal of Physiology 257 L430-L437 
Cherouny P, Ghodgaonkar R, Gurtner G and Dubin N (1988) The effect of hydrogen peroxide on prostaglandin production and contractions of the pregnant rat uterus American Joumal of Obstetrics and Gynecology 159 1390-1394

Daniel JC, Jr (1964) Early growth of rabbit trophoblast The American Naturalist 98 85-97

Denker HW and Gerdes HJ (1979) The dynamic structure of rabbit blastocyst coverings. I. Transformation during regular preimplantation development Anatomy and Embryology 157 15-34

Dey SK, Chien SM, Cox CL and Crist RD (1980) Prostaglandin synthesis in the rabbit blastocyst Prostaglandins $19449-453$

Fridhandler L (1961) Pathways of glucose metabolism in fertilized rabbit ova at various pre-implantation stages Experimental Cell Research 22 303-316

Fridhandler L, Hafez ESE and Pincus G (1957) Developmental changes in the respiratory activity of rabbit ova Experimental Cell Research 13 132-139

Halliwell B and Gutteridge JMC (1989) Free Radicals in Biology and Medicine (2nd Edn) Oxford University Press, Oxford

Hoffman LH, Strong GB, Davenport GR and Fröhlich JC (1977) Deciduogenic effect of prostaglandins in the pseudopregnant rabbit Journal of Reproduction and Fertility 50 231-237

Hoffman LH, Davenport GR and Brash AR (1984) Endometrial prostaglandins and phospholipase activity related to implantation in rabbits: effects of dexamethasone Biology of Reproduction 30 544-555

Hoos PC and Hoffman LH (1980) Temporal aspects of rabbit uterine vascular and decidual responses to blastocyst stimulation Biology of Reproduction 23 453-459

lizuka T, Kanegasaki S, Makino R, Tanaka T and Ishimura Y (1985) Pyridine and imidazole reversibly inhibit the respiratory burst in porcine and human neutrophiles: evidence for the involvement of cytochrome b558 in the reaction Biophysical and Biochemical Research Communications 130 $621-626$

Jaszczak S, Hafez ESE, Moghissi KB and Kurrie DA (1972) Concentration gradients of amino acids between the uterine and blastocoelic fluid in the rabbit Fertility and Sterility 23 405-409

Karp G, Manes C and Hahn WE (1973) RNA synthesis in the preimplantation rabbit embryo: radioautographic analysis Developmental Biology 31 404-408

Kennedy TG (1983) Embryonic signals and the initiation of blastocyst implantation Australian Journal of Biological Sciences 36 531-543

Mahler HR and Cordes E (1966) Biological Chemistry p 602. Harper and Row, New York

Manes C (1992) Cyanide-resistant reduction of nitroblue tetrazolium and hydrogen peroxide production by the rabbit blastocyst Molecular Reproducfion and Development 31 114-121
Marshall PJ, Kulmacz RJ and Lands WEM (1984) Hydroperoxides, free radicals and prostaglandin synthesis. In Oxygen Radicals in Chemistry and Biology, pp 299-308 Eds W Bors, M Saran and D Tait. W de Gruyter, Berlin

Miller JGO and Schultz GA (1987) Amino acid content of preimplantation rabbit embryos and fluids of the reproductive tract Biology of Reproduction 36 $125-129$

Morgan PM and Kane MT (1993) Protein content of rabbit embryos: one cell to peri-implantation blastocyst Journal of Reproduction and Fertility 97 101-106

Morse DE, Duncan H, Hooker N and Morse A (1977) Hydrogen peroxide induces spawning in molluscs, with activation of prostaglandin endoperoxide synthetase Science 196 298-300

Mukherjee SP (1980) Mediation of the antilipolytic and lipogenic effects of insulin in adipocytes by intracellular accumulation of hydrogen peroxide Biochemical Pharmacology 29 1239-1246

Oberley LW and Spitz DR (1985) Nitroblue tetrazolium. In Handbook of Methods for Oxygen Radical Research pp 217-225 Ed. R Greenwald. CRC Press, Boca Raton

Oster G and Oster GK (1974) Free radical production by metallic copper Contraception 10 273-280

Racowsky C and Biggers JD (1983) Are blastocyst prostaglandins produced endogenously? Biology of Reproduction 29 379-388

Rao GN and Berk BC (1992) Active oxygen species stimulate vascular smooth muscle cell growth and proto-oncogene expression Circulation Research 70 593-599

Schlafke S and Enders AC (1975) Cellular basis of interaction between trophoblast and uterus at implantation Biology of Reproduction 12 41-65

Schreck R, Rieber P and Baeuerle PA (1991) Reactive oxygen intermediates as apparently widely used messengers in the activation of the NF- $\mathrm{KB}$ transcription factor and HIV-1 EMBO Journal 10 2247-2258

Tanaka T and Knox WE (1959) The nature and mechanism of the tryptophan pyrrolase (peroxidase-oxidase) reaction of Pseudomonas and of rat liver Journal of Biological Chemistry 234 1162-1170

Tobert JA (1975) Induction of deciduomata by intrauterine copper in the rabbit Journal of Reproduction and Fertility 45 197-200

Turner E, Somers CE and Shapiro BM (1985) The relationship between a novel $\mathrm{NAD}(\mathrm{P}) \mathrm{H}$ oxidase activity of ovoperoxidase and the $\mathrm{CN}^{-}$resistant respiratory burst that follows fertilization of sea urchin eggs Journal of Biological Chemistry 26013 163-13 171

Winterhager E, Brümmer F, Dermietzel R, Hülser DF and Denker HW (1988) Gap junction formation in rabbit uterine epithelium in response to embryo recognition Developmental Biology 126 203-211

Yamamoto S and Hayaishi O (1967) Tryptophan pyrrolase of rabbit intestine Journal of Biological Chemistry 242 5260-5266 